\title{
Genome Sequence Resource of the Wide-Host-Range Anthracnose Pathogen Colletotrichum siamense
}

\author{
Yanan Meng, ${ }^{1}$ Mark L. Gleason, ${ }^{2}$ Rong Zhang, ${ }^{1}$ and Guangyu Sun ${ }^{1 \dagger}$ \\ ${ }^{1}$ State Key Laboratory of Crop Stress Biology in Arid Areas and College of Plant Protection, Northwest \\ A\&F University, Yangling, Shaanxi Province 712100, China \\ ${ }^{2}$ Department of Plant Pathology and Microbiology, lowa State University, Ames, IA 50011, U.S.A.
}

Funding:

This research was supported by National Natural Science Foundation of China (31772113) and China Agriculture Research System (CARS-27).

\begin{abstract}
Colletotrichum siamense causes fruit or foliar disease called anthracnose on a variety of plant hosts such as vegetables, fruits, ornamental plants, and others, including chili pepper, apple, American cranberry, mango, orange, papaya, guava, rubber plant, jasmine, coffee berry, and tea plants. Here, we report the first Illumina-sequenced draft genome assembly of $C$. siamense strain ICMP 18578 and its annotation. This genome sequence provides a unique resource that will be useful for future research on the evolution of Colletotrichum spp. and improvement of anthracnose management strategies.
\end{abstract}

Colletotrichum is one of the most important phytopathogenic fungal genera (Dean et al. 2012). Species in this genus can cause rots and blights on a variety of plant hosts, including cereals, grasses, vegetables, fruits, and ornamental plants, leading to severe losses in yield and quality (Hyde et al. 2009). Colletotrichum siamense was first described as a coffee berry pathogen in the $C$. gloeosporioides complex (Prihastuti et al. 2009). Later, it was also reported as causal agents of anthracnose associated with mango, custard apple, papaya, fig, neem, tea plants, chili pepper, and persimmon (Hassan et al. 2018, Liu et al. 2016a, Udayanga et al. 2013, Wang et al. 2016). In recent years, several new species which displayed a close phylogenetic relationship to $C$. siamense on various hosts have been described, including C. hymenocallidis, isolated from amaryllids (Yang et al. 2009); C. jasmine-sambac, associated with jasmine (Wikee et al. 2011); C. murrayae, isolated from orange (Peng et al. 2012); C. melanocaulon, associated with American cranberry (Doyle et al. 2013); C. dianesei, isolated from mango (Lima et al. 2013); C. endomangiferae, associated with mango (Vieira et al. 2014); and C. communis, associated with orchid tree, golden shower tree, orange, rubber plant, mango, guava, and ashoka tree (Sharma et al. 2015). Nevertheless, results based on Genealogical Concordance Phylogenetic Species Recognition (GCPSR), coalescent methods, and mating tests confirmed that all of these species mentioned above should be synonyms of $C$. siamense (Liu et al. 2016b), a worldwide pathogen causing serious diseases and losses on many economically important plant hosts. In the present study, we sequenced the type strain of $C$. siamense in order to provide a preliminary understanding of the genetic information.

C. siamense H. Prihastuti, L. Cai \& K. D. Hyde ICMP 18578 (type strain) was isolated from coffee berries (Coffea arabica L.) (Prihastuti et al. 2009) and deposited at the International Collection of Microorganisms from Plants. Highly purified genomic DNA was extracted and its genome was sequenced with the Illumina HiSeq2500 platform (Novogene, Beijing, China). The 150-bp Illumina paired-end reads (insertion length, $350 \mathrm{bp}$; filtered reads,

${ }^{\dagger}$ Corresponding author: G. Sun; sgy@ nwsuaf.edu.cn

The author(s) declare no conflict of interest.

Accepted for publication 18 March 2019.

(C) 2019 The American Phytopathological Society

\section{Keywords \\ genomics}


Table 1. Genome features of Colletotrichum siamense strain ICMP 18578

\begin{tabular}{lc} 
Variables & Statistics \\
Sequence coverage & $179 \times$ \\
Assembly size & $55,961,623 \mathrm{bp}$ \\
Number of scaffolds & 235 \\
Scaffold N50 & $927,217 \mathrm{bp}$ \\
GC content & $52.67 \%$ \\
Number of predicted genes & 17,283 \\
Repeat rate & $1.56 \%$ \\
BUSCO completeness & $99.65 \%$ \\
\hline
\end{tabular}

10.5G) were used for de novo assembly by the ABySS assembler v1.3.5 (Simpson et al. 2009) with different kmer values (50 to 101) in order to obtain the best assembly. The final draft genome consists of 235 scaffolds spanning a total assembled length of $55.96 \mathrm{Mbp}$ ( $N 50=927,217 \mathrm{bp}$, and maximum scaffold length = 2,573,469 bp), with $52.67 \% \mathrm{GC}$ content and a coverage of 179 -fold (Table 1 ), which is similar to the assembly sizes of other published Colletotrichum gloeosporioides species complex (Cannon et al. 2012) genomes, including C. fructicola Nara gc5 (55,607,143 bp) (Gan et al. 2013), C. fructicola 1104-7 (57,082,694 bp) (Liang et al. 2018), C. gloeosporioides Cg-14 (53,209,944 bp) (Alkan et al. 2013), and shorter than C. gloeosporioides SMCG1\#C (61,916,549 bp), which was sequenced with PacBio and Illumina Genome Analyzer X Ten (Huang et al. 2019). Repetitive sequence detection was performed by using Repeat Masker v4.0.5 based on libraries generated by two different strategies: de novo-based and homology-based methods. De novo repeats prediction was done using the Repeat Modeler v1.0.7 pipeline with default settings (Saha et al. 2008), and the RepeatModeler repeat library was filtered by removing repetitive gene sequences. Then RepeatMasker was used to predict and categorized repeat sequences in the current genome with the filtered custom RepeatModeler library. In addition, homology-based repeat element search was performed using RepeatMasker with the RepBase fungal library (build on 20170127). Finally, the results of the above two strategies were combined and analyzed. Approximately $1.56 \%$ of sequences were identified as repeat sequences. The completeness of assembly was evaluated using the software BUSCO v1.2 with the lineage-specific profile library fungi_odb9 (Simão et al. 2015), which is based on a set of 1,438 common fungal genes as benchmark universal single-copy orthologs. This result showed that the genome assembly is estimated to be $99.7 \%$ complete, suggesting a high degree of completeness. To predict gene structures, two different ab initio gene annotation programs-Augustus v3.1 (Stanke and Morgenstern 2005) and GeneMark-ES (Ter-Hovhannisyan et al. 2008)—were trained for use with MAKER v2.31.8 (Holt and Yandell 2011). GeneMark-ES was trained on its own genome sequence, and the gene models of the Glomerella cingulate strain 23 (Weir et al. 2012) obtained from Joint Genome Institute were used to train Augustus. The predicted results from GeneMark-ES, Augustus, and the homology proteins of the $C$. siamense genome-including C. graminicola M1.001 v1.0 (O'Connell et al. 2012), C. gloeosporioides Cg-14 v1.0 (Alkan et al. 2013) C. fructicola Nara gc5 v1.0 (Gan et al. 2013) and C. fioriniae PJ7 v1.0 (Baroncelli et al. 2014) -were combined for a final MAKER2 integration. The C. siamense genome was predicted to have 17,283 protein-coding genes; among these putative proteins, $63.08 \%$ of sequences $(n=10,902)$ having PFAM domains were predicted by InterProScan 5.2-45.0 (Jones et al. 2014), with a cut-off e-value of 1E-05. Secretome proteins are known to play important roles in fungal pathogenicity and virulence (GonzálezFernández et al. 2010). In the current study, secretomes were predicted using a custom pipeline. Proteins with a secretion signal determined by SignalP v4.1 (Petersen et al. 2011) were retained initially, then scanned for transmembrane (TM) domains using TMHMM 2.0. Proteins with no TM or one TM were exported into WoLF PSort v0.2 software (Horton et al. 2007) to predicted their localizations. Among the most likely localization with scores, proteins which were credibly positioned in the extracellular space (i.e., extracellular score $>15$ ) were chosen as secretomes. In total, 1,753 predicted proteins $(10.14 \%$ of the entire protein complement) were considered to be credible secretory proteins. The production of phytotoxic compounds by fungi is another crucial factor in plant pathogenesis (Amselem et al. 2011). Putative secondary metabolite biosynthesis genes and clusters were identified using the web-based tool antiSMASH 2.0 (Blin et al. 2013). In total, 76 secondary metabolite clusters 
were identified in the $C$. siamense genome (8 indole clusters, 10 NRPS clusters, 29 PKS clusters, 12 terpene clusters, 9 hybrid clusters, and 8 other clusters).

This Whole Genome Shotgun project has been deposited at GenBank under the accession number RJJI00000000 (BioProject: PRJNA504379; BioSample: SAMN10390762). The version described in this article is version RJJI01000000.

\section{Acknowledgments}

We thank the reviewers for their kind and helpful comments on the original manuscript and L. Cai, Institute of Microbiology, Chinese Academy of Sciences, for providing the type isolate.

\section{Literature Cited}

Alkan, N., Meng, X., Friedlander, G., Reuveni, E., Sukno, S., Sherman, A., Thon, M., Fluhr, R., and Prusky, D. 2013. Global aspects of pacC regulation of pathogenicity genes in Colletotrichum gloeosporioides as revealed by transcriptome analysis. Mol. Plant-Microbe Interact. 26:1345-1358.

Amselem, J., Cuomo, C. A., van Kan, J. A. L., Viaud, M., Benito, E. P., Couloux, A., Coutinho, P. M., de Vries, R. P., Dyer, P. S., Fillinger, S., Fournier, E., Gout, L., Hahn, M., Kohn, L., Lapalu, N., Plummer, K. M., Pradier, J. M., Quévillon, E., Sharon, A., Simon, A., ten Have, A., Tudzynski, B., Tudzynski, P., Wincker, P., Andrew, M., Anthouard, V., Beever, R. E., Beffa, R., Benoit, I., Bouzid, O., Brault, B., Chen, Z., Choquer, M., Collémare, J., Cotton, P., Danchin, E. G., Da Silva, C., Gautier, A., Giraud, C., Giraud, T., Gonzalez, C., Grossetete, S., Güldener, U., Henrissat, B., Howlett, B. J., Kodira, C., Kretschmer, M., Lappartient, A., Leroch, M., Levis, C., Mauceli, E., Neuvéglise, C., Oeser, B., Pearson, M., Poulain, J., Poussereau, N., Quesneville, H., Rascle, C., Schumacher, J., Ségurens, B., Sexton, A., Silva, E., Sirven, C., Soanes, D. M., Talbot, N. J., Templeton, M., Yandava, C., Yarden, O., Zeng, Q., Rollins, J. A., Lebrun, M. H., and Dickman, M. 2011. Genomic analysis of the necrotrophic fungal pathogens Sclerotinia sclerotiorum and Botrytis cinerea. PLoS Genet. 7:e1002230.

Baroncelli, R., Sreenivasaprasad, S., Sukno, S. A., Thon, M. R., and Holub, E. 2014. Draft genome sequence of Colletotrichum acutatum sensu lato (Colletotrichum fioriniae). Genome Announce. 2:e00112-14.

Blin, K., Medema, M. H., Kazempour, D., Fischbach, M. A., Breitling, R., Takano, E., and Weber, T. 2013. antiSMASH 2.0-A versatile platform for genome mining of secondary metabolite producers. Nucleic Acids Res. 41:W204-W212.

Cannon, P. F., Damm, U., Johnston, P. R., and Weir, B. S. 2012. Colletotrichum-Current status and future directions. Stud. Mycol. 73:181-213.

Dean, R., Van Kan, J. A., Pretorius, Z. A., Hammond-Kosack, K. E., Di Pietro, A., Spanu, P. D., Rudd, J. J., Dickman, M., Kahmann, R., Ellis, J., and Foster, G. D. 2012. The Top 10 fungal pathogens in molecular plant pathology. Mol. Plant Pathol. 13:414-430.

Doyle, V. P., Oudemans, P. V., Rehner, S. A., and Litt, A. 2013. Habitat and host indicate lineage identity in Colletotrichum gloeosporioides s.l. from wild and agricultural landscapes in North America. PLoS One 8:e62394.

Gan, P., Ikeda, K., Irieda, H., Narusaka, M., O'Connell, R. J., Narusaka, Y., Takano, Y., Kubo, Y., and Shirasu, K. 2013. Comparative genomic and transcriptomic analyses reveal the hemibiotrophic stage shift of Colletotrichum fungi. New Phytol. 197:1236-1249.

González-Fernández, R., Prats, E., and Jorrín-Novo, J. V. 2010. Proteomics of plant pathogenic fungi. J. Biomed. Biotechnol. 2010: Article 932527.

Hassan, O., Jeon, J. Y., Chang, T., Shin, J. S., Oh, N. K., and Lee, Y. S. 2018. Molecular and morphological characterization of Colletotrichum species in the Colletotrichum gloeosporioides complex associated with persimmon anthracnose in South Korea. Plant Dis. 102:1015-1024.

Holt, C., and Yandell, M. 2011. MAKER2: An annotation pipeline and genome-database management tool for second-generation genome projects. BMC Bioinf. 12:491.

Horton, P., Park, K. J., Obayashi, T., Fujita, N., Harada, H., Adams-Collier, C. J., and Nakai, K. 2007. WoLF PSORT: Protein localization predictor. Nucleic Acids Res. 35:W585-W587.

Huang, L., Kim, K. T., Yang, J. Y., Song, H., Choi, G., Jeon, J., Cheong, K., Ko, J., Xu, H., and Lee, Y. H. 2019. A high-quality draft genome sequence of Colletotrichum gloeosporioides sensu stricto SMCG1\#C, a causal agent of anthracnose on Cunninghamia lanceolata in China. Mol. Plant-Microbe Interact. 32:139-141.

Hyde, K. D., Cai, L., Cannon, P. F., Crouch, J. A., Crous, P. W., Damm, U., Goodwin, P. H., Chen, H., Johnston, P. R., Jones, E. B. G., Liu, Z. Y., McKenzie, E. H. C. Moriwaki, J., Noireung, P., Pennycook, S. R., Pfenning, L. H., Prihastuti, H., Sato, T., Shivas, R. G., Tan, Y. P., Taylor, P. W. J., Weir, B. S., Yang, Y. L., and Zhang, J. Z. 2009. Colletotrichum - names in current use. Fungal Divers. 39:147-182. Jones, P., Binns, D., Chang, H. Y., Fraser, M., Li, W., McAnulla, C., McWilliam, H., Maslen, J., Mitchell, A., Nuka, G., Pesseat, S., Quinn, A. F., Sangrador-Vegas, A., Scheremetjew, M., Yong, S. Y., Lopez, R., and Hunter, S. 2014. InterProScan 5: Genome-scale protein function classification. Bioinformatics 30:1236-1240.

Liang, X., Wang, B., Dong, Q., Li, L., Rollins, J. A., Zhang, R., and Sun, G. 2018. Pathogenic adaptations of Colletotrichum fungi revealed by genome wide gene family evolutionary analyses. PLoS One 13:e0196303.

Lima, N. B., de A. Batista, M. V., De Morais, M. A., Barbosa, M. A. G., Michereff, S. J., Hyde, K. D., and Câmara, M. P. S. 2013. Five Colletotrichum species are responsible for mango anthracnose in northeastern Brazil. Fungal Divers. 61: 75-88.

Liu, F., Tang, G., Zheng, X., Li, Y., Sun, X., Qi, X., Zhou, Y., Xu, J., Chen, H., Chang, X., Zhang, S., and Gong, G. 2016a. Molecular and phenotypic characterization of Colletotrichum species associated with anthracnose disease in peppers from Sichuan Province, China. Sci. Rep. 6: Article 32761.

Liu, F., Wang, M., Damm, U., Crous, P. W., and Cai, L. 2016b. Species boundaries in plant pathogenic fungi: A Colletotrichum case study. BMC Evol. Biol. 16:81.

O'Connell, R. J., Thon, M. R., Hacquard, S., Amyotte, S. G., Kleemann, J., Torres, M. F., Damm, U., Buiate, E. A., Epstein, L., Alkan, N., Altmüller, J., AlvaradoBalderrama, L., Bauser, C. A., Becker, C., Birren, B. W., Chen, Z., Choi, J., Crouch, J. A., Duvick, J. P., Farman, M. A., Gan, P., Heiman, D., Henrissat, B., Howard, R. J., Kabbage, M., Koch, C., Kracher, B., Kubo, Y., Law, A. D., Lebrun, M. H., Lee, Y. H., Miyara, I., Moore, N., Neumann, U., Nordström, K., Panaccione, D. G., Panstruga, R., Place, M., Proctor, R. H., Prusky, D., Rech, G., Reinhardt, R., Rollins, J. A., Rounsley, S., Schardl, C. L., Schwartz, D. C., Shenoy, N., Shirasu, K., Sikhakolli, U. R., Stüber, K., Sukno, S. A., Sweigard, J. A., Takano, Y., Takahara, H., Trail, F., van der Does, H. C., Voll, L. M., Will, I., Young, S., Zeng, Q., Zhang, J., Zhou, S., Dickman, M. B., Schulze-Lefert, P., Ver Loren van Themaat, E., Ma, L. J., and Vaillancourt, L. J. 2012. Lifestyle transitions in plant pathogenic Colletotrichum fungi deciphered by genome and transcriptome analyses. Nat. Genet. 44:1060-1065.

Peng, L., Yang, Y., Kevin, D. H., Bahkali, A. H., and Liu, Z. 2012. Colletotrichum species on Citrus leaves in Guizhou and Yunnan provinces, China. Cryptogam. Mycol. 33:267-283.

Petersen, T. N., Brunak, S., von Heijne, G., and Nielsen, H. 2011. SignalP 4.0: Discriminating signal peptides from transmembrane regions. Nat. Methods 8 : 785-786.

Prihastuti, H., Cai, L., Chen, H., McKenzie, E. H. C., and Hyde, K. D. 2009. Characterization of Colletotrichum species associated with coffee berries in northern Thailand. Fungal Divers. 39:89-109.

Saha, S., Bridges, S., Magbanua, Z. V., and Peterson, D. G. 2008. Empirical comparison of $a b$ initio repeat finding programs. Nucleic Acids Res. 36: 2284-2294.

Sharma, G., Pinnaka, A. K., and Shenoy, B. D. 2015. Resolving the Colletotrichum siamense species complex using ApMat marker. Fungal Divers. 71:247-264. 
Simão, F. A., Waterhouse, R. M., loannidis, P., Kriventseva, E. V., and Zdobnov, E. M. 2015. BUSCO: Assessing genome assembly and annotation completeness with single-copy orthologs. Bioinformatics 31:3210-3212.

Simpson, J. T., Wong, K., Jackman, S. D., Schein, J. E., Jones, S. J. M., and Birol, I. 2009. ABySS: A parallel assembler for short read sequence data. Genome Res. 19:1117-1123.

Stanke, M., and Morgenstern, B. 2005. AUGUSTUS: A web server for gene prediction in eukaryotes that allows user-defined constraints. Nucleic Acids Res. 33:W465-W467.

Ter-Hovhannisyan, V., Lomsadze, A., Chernoff, Y. O., and Borodovsky, M. 2008. Gene prediction in novel fungal genomes using an ab initio algorithm with unsupervised training. Genome Res. 18:1979-1990.

Udayanga, D., Manamgoda, D. S., Liu, X., Chukeatirote, E., and Hyde, K. D. 2013. What are the common anthracnose pathogens of tropical fruits? Fungal Divers. 61:165-179

Vieira, W. A. S., Michereff, S. J., de Morais, M. A., Hyde, K. D., and Camara, M. P. S. 2014. Endophytic species of Colletotrichum associated with mango in northeastern Brazil. Fungal Divers. 67:181-202.
Wang, Y. C., Hao, X. Y., Wang, L., Bin Xiao, Wang, X. C., and Yang, Y. J. 2016. Diverse Colletotrichum species cause anthracnose of tea plants (Camellia sinensis (L.) O. Kuntze) in China. Sci. Rep. 6: Article 35287.

Weir, B. S., Johnston, P. R., and Damm, U. 2012. The Colletotrichum gloeosporioides species complex. Stud. Mycol. 73:115-180.

Wikee, S., Cai, L., Pairin, N., McKenzie, E. H. C., Su, Y. Y., Chukeatirote, E., Thi, H. N., Bahkali, A. H., Moslem, M. A., Abdelsalam, K., and Hyde, K. D. 2011. Colletotrichum species from jasmine (Jasminum sambac). Fungal Divers. 46: 171-182.

Yang, Y. L., Liu, Z. Y., Cai, L., Hyde, K. D., Yu, Z. N., and McKenzie, E. H. C. 2009. Colletotrichum anthracnose of Amaryllidaceae. Fungal Divers. 39:123-146.

\section{Author-Recommended Internet Resources}

Repeat Masker: http://www.repeatmasker.org

Joint Genome Institute: https://genome.jgi.doe.gov/programs/fungi/index.jsf

TMHMM 2.0: http://www.cbs.dtu.dk/services/TMHMM 